\title{
sensors
}

ISSN 1424-8220

(C) 2008 by MDPI

www.mdpi.org/sensors

Full Paper

\section{Study of Copper and Purine-Copper Complexes on Modified Carbon Electrodes by Cyclic and Elimination Voltammetry}

\author{
Libuse Trnkova $^{1{ }^{1 *}, \text { Lenka Zerzankova }}{ }^{1}$, Filip Dycka ${ }^{1}$, Radka Mikelova ${ }^{1}$ and Frantisek Jelen ${ }^{2}$ \\ 1 Department of Chemistry, Faculty of Science, Masaryk University, Kotlarska 2, 61137 Brno, \\ Czech Republic \\ 2 Institute of Biophysics, Academy of Sciences of the Czech Republic, v.v.i., Kralovopolska 135, \\ Brno 612 65, Czech Republic \\ * Author to whom correspondence should be addressed; E-mail: libuse@chemi.muni.cz
}

Received: 30 December 2007 / Accepted: 15 January 2008 / Published: 24 January 2008

\begin{abstract}
Using a paraffin impregnated graphite electrode (PIGE) and mercury-modified pyrolytic graphite electrode with basal orientation (Hg-PGEb) copper(II) and $\mathrm{Cu}$ (II)-DNA purine base solutions have been studied by cyclic (CV) and linear sweep voltammetry (LSV) in connection with elimination voltammetry with linear scan (EVLS). In chloride and bromide solutions ( $\mathrm{pH}$ ), the redox process of $\mathrm{Cu}$ (II) proceeded on PIGE with two cathodic and two anodic potentially separated signals. According to the elimination function $\mathrm{E} 4$, the first cathodic peak corresponds to the reduction $\mathrm{Cu}(\mathrm{II})+\mathrm{e}^{-} \rightarrow \mathrm{Cu}$ (I) with the possibility of fast disproportionation $2 \mathrm{Cu}(\mathrm{I}) \rightarrow \mathrm{Cu}(\mathrm{II})+\mathrm{Cu}(0)$. The $\mathrm{E} 4$ of the second cathodic peak signalized an electrode process controlled by a surface reaction. The electrode system of $\mathrm{Cu}$ (II) on $\mathrm{Hg}-\mathrm{PGEb}$ in borate buffer ( $\mathrm{pH}$ 9.2) was characterized by one cathodic and one anodic peak. Anodic stripping voltammetry (ASV) on PIGE and cathodic stripping voltammetry (CSV) on $\mathrm{Hg}$-PGEb were carried out at potentials where the reduction of copper ions took place and $\mathrm{Cu}(\mathrm{I})$-purine complexes were formed. By using ASV and CSV in combination with EVLS, the sensitivity of $\mathrm{Cu}(\mathrm{I})$-purine complex detection was enhanced relative to either ASV or CSV alone, resulting in higher peak currents of more than one order of magnitude. The statistical treatment of CE data was used to determine the reproducibility of measurements. Our results show that EVLS in connection with the stripping procedure is useful for both qualitative and quantitative microanalysis of purine derivatives and can also reveal details of studied electrode processes.
\end{abstract}


Keywords: Copper-purine complexes, Paraffin-impregnated graphite electrode, Mercuryfilm electrode, Anodic and cathodic stripping techniques, Elimination voltammetry, Confidence ellipse.

\section{Introduction}

Nucleic acid bases and some of their derivatives can be detected by stripping analysis with mercury electrodes. Using cathodic stripping voltammetry (CSV) in connection with cyclic voltammetry (CV) or differential pulse voltammetry (DPV), we were able to detect purine and pyrimidine bases at very low concentrations [1]. Voltammetric ultra-trace determination of some nucleic bases in the presence of $\mathrm{Cu}$ (II) using a mercury electrode or solid amalgam electrodes has been also described [2-6]. Determination is based on the formation of purine-copper complex at the electrode surface and subsequent stripping resulting in a voltammetric signal suitable for analytical purposes $[3,7,8]$.

As mercury and amalgam electrodes are avoided for both industrial and scientific purposes in many countries around the world, new types of working electrodes for analysis of nucleic acids and their components are needed. Modified carbon electrodes are widely used in many applications in bioanalysis. A number of protocols describing modification of these electrodes have been published [9]. Recently, paraffin-impregnated carbon electrodes (PIGE) have been used for kinetic measurements [10-13] and for electrochemical studies where obtained data were evaluated by elimination voltammetry [14-17]. Electrochemical characteristics of PIGE electrodes are comparable with other carbon electrodes; their advantages include easy of preparation and very low negative potential limits [18].

The electrochemical oxidation of adenine and guanine and other purine derivatives at carbon electrodes have been reported [19-23]. Formation of complexes of these compounds with metals, including copper, has been studied extensively by electrochemical methods [3,7,24-26]. Species $\mathrm{Cu}$ (II) can be reduced to $\mathrm{Cu}(\mathrm{I})$ and in the presence of purines, such as adenine or guanine, $\mathrm{Cu}(\mathrm{I})$ reacts with purines to form insoluble compounds that accumulate on electrode surfaces [7,24]. This approach can be applied for the detection of oligodeoxynucleotide (ODN) after acid hydrolysis which releases purine bases from the ODN chain $[6,27,28]$.

In this paper, elimination voltammetry with linear scan (EVLS) [29-32] in conjunction with an adsorptive stripping technique was used to detect two purine derivatives in the presence of copper(II). The measurements were carried out with two modified carbon electrodes: paraffin-impregnated graphite electrodes (PIGE) and mercury-modified pyrolytic graphite electrodes with basal orientation (Hg-PGEb). To understand the complex electrode processes we investigated redox behavior of $\mathrm{Cu}(\mathrm{II})$ salts at both electrodes. 


\section{Material and Methods}

\subsection{Chemicals}

Chemicals purchased from Sigma-Aldrich were of ACS quality. The solutions contained $\mathrm{CuCl}_{2}$ in $\mathrm{NaCl}$ or $\mathrm{CuBr}_{2}$ in $\mathrm{NaBr}\left(\mathrm{pH}\right.$ 6.0) and $\mathrm{CuSO}_{4}$ in $0.05 \mathrm{M}$ sodium tetraborate (pH 9.2) for PIGE and $\mathrm{Hg}-\mathrm{PGEb}$, respectively, and were prepared using Millipore water (Direct- $\mathrm{Q}^{\circledR} 3$ Ultrapure Water Systems). The $\mathrm{pH}$ was adjusted by $0.2 \mathrm{M} \mathrm{NaOH}$ and measured by means of $\mathrm{pH}$ meter CyberScan (Eutech Instruments, PC 5500) with Hamilton Single Pore Glass Electrode and temperature sensor Accumet.

\subsection{Instrumentation}

The voltammetric measurements were carried out with the AUTOLAB electrochemical system (Ecochemie, Utrecht, Netherlands) equipped with a potentiostat/galvanostat PGStat30. A threeelectrode system was used. The working electrode was a paraffin-impregnated graphite electrode (PIGE) with an area of $12.56 \mathrm{~mm}^{2}$ or a pyrolytic graphite electrode with basal orientation modified by a mercury layer (Hg-PGEb) with an area of $30 \mathrm{~mm}^{2}$. A platinum wire served as the counter electrode. The reference electrode was $\mathrm{Ag}|\mathrm{AgCl}| 3 \mathrm{M} \mathrm{KCl}$.

\subsection{Preparation of graphite electrodes}

The porous graphite cylinder was $150 \mathrm{~mm}$ long and $6 \mathrm{~mm}$ in diameter, mensural electric resistance was $1000 \mu \Omega / \mathrm{cm}$, and porosity $30 \%$. The electrode contained the following admixtures (ppm): B, 0.01 ; $\mathrm{Ca}, 0.1 ; \mathrm{Cu}, 0.1 ; \mathrm{Fe}, 0.2 ; \mathrm{Mg}, 0.01 ; \mathrm{Si}, 0.1 ; \mathrm{Al}, 0.05 ; \mathrm{Ti}, 0.01$. The graphite rod was impregnated with paraffin to fill the pores and to suppress the background current [9,33,34]. The graphite was impregnated with paraffin at about $150-200{ }^{\circ} \mathrm{C}$ for 3 hours [35]. This procedure was applied at low pressure provided by an oil pump. The contact surface of the graphite electrode with the electrolyte was mechanically regenerated, cleaned, and washed by using abrasive paper (granularity of P1000), filter paper, and distilled water, prior to measurement. Before a measurement, solutions were deaerated by argon ( 99.996 vol. \% purity) for 15 minutes. The basal oriented pyrolytic graphite rod was obtained from GE-Advance Ceramics. The surface of the pyrolytic graphite electrode with basal orientation (PGEb) was refreshed with adhesive tape without mechanical polishing and sonicated in triply distilled water $(30 \mathrm{~s})$. The electrodeposition of the mercury on PGEb surface was carried out in $30 \mathrm{mM}$ $\mathrm{Hg}\left(\mathrm{NO}_{3}\right)_{2}$ solution using the potentiostat with a three-electrode system. The deposition potential was $-1.2 \mathrm{~V}$ vs. $\mathrm{Ag}|\mathrm{AgCl}| 3 \mathrm{M} \mathrm{KCl}$. The thickness $h$ of the mercury layer was controlled by a change of the deposition time $t$ and current value $I$ with respect to the Faraday law:

$$
h=\frac{I t M}{n \rho A F}
$$

where $h$ is the thickness of the $\mathrm{Hg}$ film (cm), $I$ the current, $t$ the time of electrolysis, $M$ the relative molar mass of $\mathrm{Hg}, n$ the number of electrons transferred, $\rho$ the density of $\mathrm{Hg}\left(\mathrm{g} / \mathrm{cm}^{3}\right), A$ the area of the 
electrode $\left(\mathrm{cm}^{2}\right)$, and $F$ is the Faraday constant. The geometrical areas A of the Hg-PGEb were $0.3 \mathrm{~cm}^{2}$. Before measurements, the $\mathrm{Hg}-\mathrm{PGEb}$ was repetitively scanned (20 cycles) in the potential region from 0 to $-1.80 \mathrm{~V}$ in $0.05 \mathrm{M}$ sodium tetraborite.

The GPES 4.9 Autolab software was used for measurements and for processing (smoothing) of recorded voltammetric curves and treatment of data.

\subsection{Methods}

\subsubsection{Elimination voltammetry with linear scan}

The elimination voltammetry with linear scan (EVLS), as a mathematical transformation of voltammetric curves, can be used to eliminate some chosen current components and to conserve the others. This transformation arises from the different dependence of partial current on scan rate and is based on the two presumptions [36]:

a) A total voltammetric current $I$ can be given as a sum of particular currents $I_{j}$ :

$$
I=\sum_{j=1}^{n} I_{j}=I_{d}+I_{c}+I_{k}+\ldots
$$

where $I_{d}, I_{c}$, and $I_{k}$ are the diffusion, charging, and kinetic currents, respectively;

b) A particular current $I_{j}$ can be expressed as a product of two functions-potential function $Y_{j}(E)$ and scan rate function $W_{j}(v)$ :

$$
I_{j}=Y_{j}(E) \cdot W_{j}(v)
$$

Based on the dependence of partial current on scan rate, equation (2) can be rewritten:

$$
I=Y_{d}(E) \cdot v^{1 / 2}+Y_{c}(E) \cdot v^{1}+Y_{k}(E) \cdot v^{0}+\ldots
$$

Using an elimination function $f(I)$ containing a linear combination of two or three currents measured at two or three scan rates, the elimination procedure yields a new curve that allows deeper characterization of electrode processes and/or enhancement of CV or LSV responses. The theory of EVLS was published ten years ago and has been developed and improved with applications described in a number of published works [14,15,17,29,31,32,37-44]. It was found that the EVLS transformation E4 (conservation of the diffusion current and elimination of kinetic and charging currents, eq. 5) is very sensitive function not only in electroanalysis but also in the study of electrode processes. Even in the case of electroactive species adsorbed on electrode surfaces, the elimination function E4 yields a signal (peak-counterpeak) that increases substantially the sensitivity of voltammetric responses and allows separation of overlapped signals [31,32,39,41,43-45]. For the multiplayer 2, the elimination function $\mathrm{E} 4$ corresponds to the linear combination: 


$$
f(I)=-11,657 I_{v_{r e f} / 2}+17,485 I_{v_{\text {ref }}}-5,8284 I_{2 v_{\text {ref }}}
$$

where $I_{v_{r e f} / 2}, I_{v_{r e f}}$, and $I_{2 v_{\text {ref }}}$ are currents measured at half of reference scan rate, reference scan rate, and two times of reference scan rate, respectively. The theoretical EVLS curve for adsorbed electroactive species has been described in our previous publications [31,32,39,41]. From an experimental point of view, the EVLS procedure was carried out by recording three voltammetric curves at different scan rates; the other experimental parameters, such as potential step, potential range, and equilibrium time, were identical for all three scan rates. One of reference scan rates was chosen as the reference scan rate $\left(v_{\text {ref }}\right)$ and elimination functions were calculated in Microsoft Excel with MACRA program for three polarization rates $\left(1 / 2 v_{\text {ref }}, v_{\text {ref }}, 2 v_{\text {ref }}\right)$.

\subsubsection{Confidence ellipse}

Method of a confidence ellipse (CE) was used for the statistical processing of measured data. Using $\mathrm{CE}$ procedure, multidimensional data such as cyclic voltammetric curves are transformed into twodimensional data by Fourier Transformation (FT). Each curve can be expressed as a sum of chosen cosines and sinus functions:

$$
F_{k}=\sum_{j=0}^{m-1} A_{j} \cos \frac{2 \pi j k}{m}+i \sum_{j=0}^{m-1} A_{j} \sin \frac{2 \pi j k}{m}
$$

where $A_{j}$ is amplitude of the curve at a particular point, $m$ is total number of points which determines the curve, and the parameter $k$ can take values from 0 to $m$ [46]. The curve determined by $m$ points with amplitude $A$ is transformed into coordinates $x f_{k}$ and $y f_{k}$. When curves are similar and differ from each other only by the multiplication factor, then the curves with coefficient $k=1$ are important and determine the character of the curve. For the first coefficient in FT the transformed curve is represented by a single point with coordinates $x f_{1}$ and $y f_{1}$ (i.e., $F_{1}=x f_{1}+i y f_{1}$ )) and from $n$ voltammetric curves we obtain $n$ points. Using orthogonal regression, these points are linked by a line with the slope $b_{T}$ :

$$
b_{T}=\frac{S_{y}-S_{x}}{2 S_{x y}} \pm \sqrt{1+\left(\frac{S_{y}-S_{x}}{2 S_{x y}}\right)^{2}}
$$

where $S_{x}=\sum x_{c}^{2}, S_{y}=\sum y_{c}^{2}, \quad S_{x y}=\sum x_{c} y_{c}$ and $x_{c}=x_{i}-\bar{x} ; y_{c}=y_{i}-\bar{y}$. The set of points is rotated to bring the regression line into the horizontal position (i.e., the x-axis). New coordinates of points are now $x_{r}$ and $y_{r}$.

$$
\left[\begin{array}{ll}
x_{r} & y_{r}
\end{array}\right]=\left[\begin{array}{ll}
x_{c} & y_{c}
\end{array}\right]\left[\begin{array}{cc}
\cos (\varphi) & -\sin (\varphi) \\
\sin (\varphi) & \cos (\varphi)
\end{array}\right]
$$

where $\varphi=\operatorname{tg}\left(b_{T}\right)$. The points are surrounded by $95 \%(99 \%)$ confidence ellipses, thus the half axes are twice (three) times the standard deviations Standard Error of Estimate Longitudinal (SEEL) and Standard Error of Estimate Transverse (SEET): 
$S E E L=(P+M) / 2$

SEET $=(P-M) / 2$

$$
P=\sqrt{\frac{\left(S_{x}+S_{y}+2 \sqrt{S_{x} S_{y}-S_{x y}^{2}}\right)}{(n-1)}} \quad M=\sqrt{\frac{\left(S_{x}+S_{y}-2 \sqrt{S_{x} S_{y}-S_{x y}^{2}}\right)}{(n-1)}}
$$

A backward rotation will bring the points together with ellipses into the original position. The ellipse ( $95 \%$ reliability) is characterized by its area and the ratio of SEEL to SEET. Using voltammetric data the CE method has been applied to electrochemical analysis of the d(GCGAAGC) hairpin [44]. Confidence ellipses were calculated in MATLAB 6.5 program. The supplement program OUTLY was used for the elimination of points outside CE.

\subsubsection{Medusa}

The program MEDUSA (Make Equilibrium Diagrams Using Sophisticated Algorithms) was used for the construction of a distribution diagram of different $\mathrm{Cu}$ chemical forms present in corresponding electrolytes. The basic parameters, including equilibrium constants that are necessary for the calculation of distribution diagrams are in the program database. The program author is Ignasi Puigdomenech from the Inorganic Chemistry of Royal Institute of Technology, Stockholm, Sweden. The MEDUSA program is the free ware and is available on http: \www.kemi.kth.se/medusa .

\section{Results and Discussion}

\subsection{Electrode process of copper ions on PIGE}

For this study, $\mathrm{Cu}(\mathrm{II})$ ions and their complexes with purine were evaluated on paraffin-impregnated graphite electrodes (PIGE) and effects of $\mathrm{pH}$, the type and concentration of supporting electrolyte, the polarization rate, and accumulation parameters were tested. Cyclic voltammograms with reduction and oxidation $\mathrm{Cu}$ signals were recorded in the potential window from -1.0 to $1.0 \mathrm{~V}$ vs. $\mathrm{Ag} / \mathrm{AgCl} / 3 \mathrm{M} \mathrm{KCl}$. Whereas cyclic voltammograms of $\mathrm{CuSO}_{4}$ in sulphate electrolytes showed only one anodic and one cathodic signal, $\mathrm{CuCl}_{2}$ in chloride electrolytes gave two reduction $\left(\mathrm{c}_{1}, \mathrm{c}_{2}\right)$ and two oxidation signals $\left(\mathrm{a}_{1}, \mathrm{a}_{2}\right.$ ) (Figure 1). The values of peak potentials were strongly dependent on $\mathrm{Cu}$ (II) and chloride concentrations, scan rate, and $\mathrm{pH}$. It is noteworthy that the behavior of $\mathrm{Cu}(\mathrm{II})$ with chloride as a supporting electrolyte was similar to that with bromide. According to chemical distribution diagrams constructed by MEDUSA program, $\mathrm{Cu}$ (II) signals on PIGE are strongly affected by $\mathrm{Cu}$-halogen complexes. The $\mathrm{pH}$ and the $\mathrm{CuX}_{2}$ concentration were the most important parameters. The separation of cathodic and anodic peaks can be caused by a specific catalytic effect of halogenide anions $\mathrm{X}^{-}$ (chlorides and bromides), which consists in the stronger attraction of positive charged species such as $\mathrm{Cu}(\mathrm{II}), \mathrm{CuX}$ (I) from solutions on the one hand and on the displacement of $\mathrm{X}^{-}$from an electrode surface on the other [16,47]. Within the range from $0.01 \mathrm{mM}$ to $1 \mathrm{mM} \mathrm{CuCl}_{2}$, the dependences of peak heights on concentration were linear for cathodic and anodic signals. The $\mathrm{pH}$ dependence showed that alkaline solutions $(\mathrm{pH}>8)$ did not encourage the formation of CV signals. This fact was supported by the distribution diagram MEDUSA which predicted lower concentrations of $\mathrm{Cu}$ (II) and/or $\mathrm{CuX}$ (I) due to 
the formation of hydroxo-complexes. Moreover, above $\mathrm{pH} \mathrm{8}$, the hydrolysis with the formation of $\mathrm{CuO} \cdot \mathrm{H}_{2} \mathrm{O}$ takes place. The effect of $\mathrm{pH}$ on the separation of redox $\mathrm{Cu}$ peaks on vitreous carbon electrode was previously described [48].

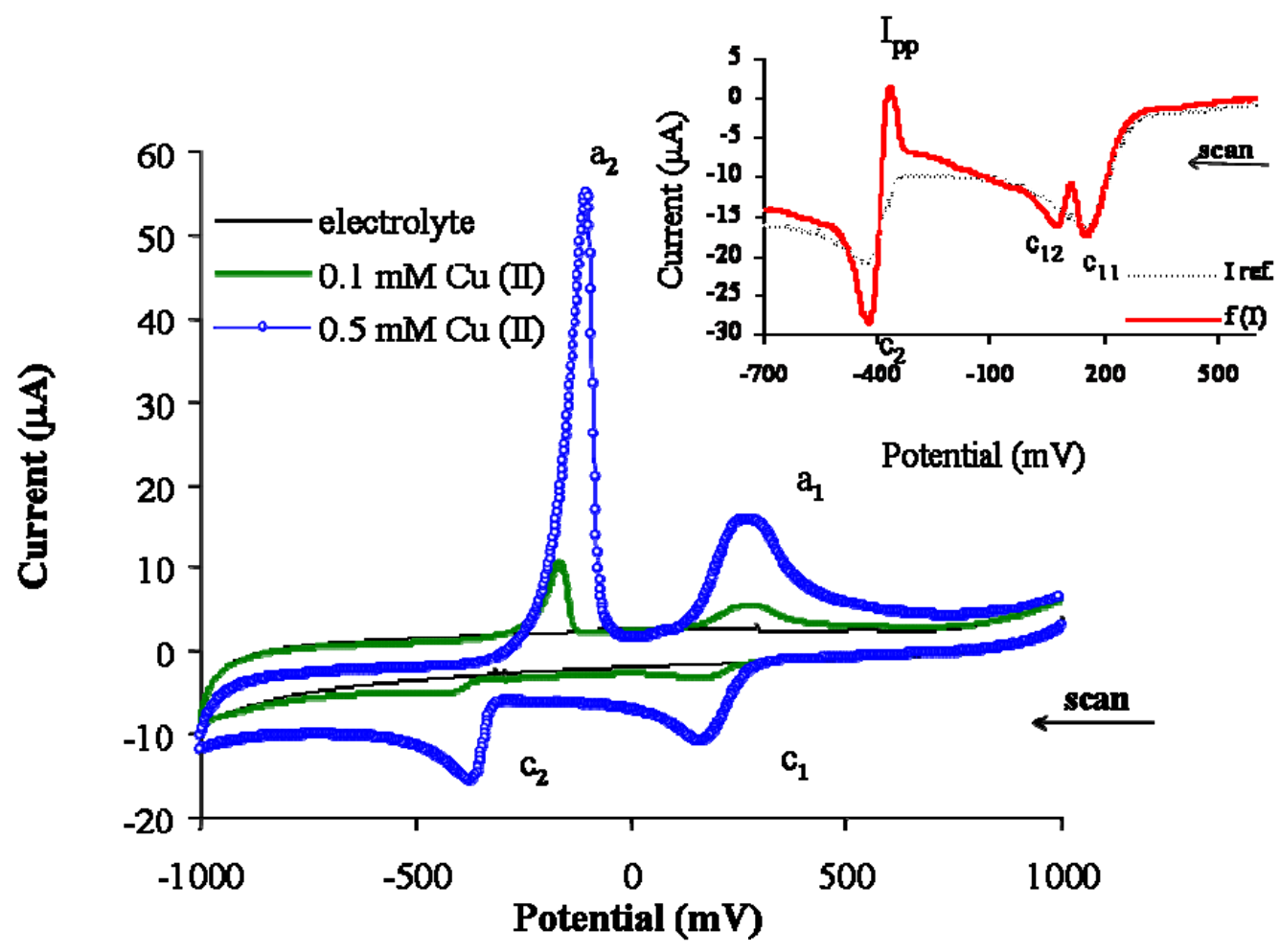

Figure 1. Cyclic voltammograms of $0.1 \mathrm{mM}$ and $0.5 \mathrm{mM} \mathrm{CuCl} \mathrm{Cl}_{2}$ on PIGE, scan rate $50 \mathrm{mV} / \mathrm{s}, \mathrm{c}_{1}$ and $\mathrm{c}_{2}$ and $\mathrm{a}_{1}$ and $\mathrm{a}_{2}$ are cathodic and anodic signals, respectively. Supporting electrolyte was $0.5 \mathrm{M} \mathrm{NaCl}$. Insert: LSV ( $\left.\mathrm{I}_{\mathrm{ref}}\right)$ and corresponding EVLS curve $\mathrm{f}(\mathrm{I})$ of $\mathrm{Cu}$ (II) reduction of $0.5 \mathrm{mM} \mathrm{CuCl}_{2}$, reference scan rate $100 \mathrm{mV} / \mathrm{s}$. The $\mathrm{I}_{\mathrm{pp}}$ is EVLS pre-peak, $\mathrm{c}_{11}$ and $\mathrm{c}_{12}$ are EVLS signals of $\mathrm{c}_{1}$. Voltammetric measurements were performed at a scan rate of $100 \mathrm{mV} / \mathrm{s}$, starting potential $1 \mathrm{~V}$, accumulation time $60 \mathrm{~s}, \mathrm{pH} 6.0$, and room temperature $\left(25^{\circ} \mathrm{C}\right)$. For the EVLS procedure, scan rates of 50, 100, and $200 \mathrm{mV} / \mathrm{s}$ were used.

Excellent resolution of cathodic and anodic signals was observed in chlorides, and therefore the following experiments were carried out in this electrolyte. The apparent effect of scan rate on peak heights was used to find the rate determining step $(r d s)$ of the individual processes. For the first cathodic $\left(\mathrm{c}_{1}\right)$ and its corresponding anodic process $\left(\mathrm{a}_{1}\right)$, the scan rate exponent $(0.47$ and 0.48$)$ revealed that both processes are controlled by diffusion. For the second redox processes, the exponents 0.28 and 0.35 for $\mathrm{c}_{2}$ and $\mathrm{a}_{2}$, respectively, indicated the processes in which kinetics take place. For deeper insight into these processes the EVLS was utilized. The application of the elimination function E4 (Eq. 2), which eliminates simultaneously $I_{c}$ and $I_{k}$ with conserved $I_{d}$, for the cathodic processes is shown in the insert in Figure 1. Experiments were performed at scan rates of 50, 100, and $200 \mathrm{mV} / \mathrm{s}$; the reference scan rate was $100 \mathrm{mV} / \mathrm{s}$. 
The elimination procedure divided $\mathrm{c}_{1}$ signal into two peaks $\left(\mathrm{c}_{11}\right.$ and $\mathrm{c}_{12}$ ). The EVLS signal for $\mathrm{c}_{2}$ showed a pre-peak which passed into higher peak than original one. It was found that peaks $\mathrm{c}_{11}$ and $\mathrm{c}_{12}$ were dependent on scan rates and $\mathrm{Cu}(\mathrm{II})$ concentrations. We propose that peak I corresponds to the reduction of $\mathrm{Cu}$ (II) (i.e., $\mathrm{Cu}(\mathrm{II})+\mathrm{e} \rightarrow \mathrm{Cu}(\mathrm{I})$ ). According to computer calculations the concentrations of $\mathrm{Cu}(\mathrm{I})$ as species $\mathrm{CuCl}_{2}{ }^{-}, \mathrm{CuCl}_{3}{ }^{2-}$, and $\mathrm{Cu}_{2} \mathrm{Cl}_{4}{ }^{2-}$ are higher than $\mathrm{Cu}$ (II) and $\mathrm{CuCl}(\mathrm{s})$ concentrations [49]. It is supported by founding that $\mathrm{Cu}$ (II) species dominated at chloride concentrations bellow $1 \mathrm{mM}$ and that soluble $\mathrm{Cu}(\mathrm{I})$ species dominated at chloride concentrations above about $100 \mathrm{mM}$. The onecharged cuprum ions can undergo the disproportionation reaction: $2 \mathrm{Cu}(\mathrm{I}) \rightarrow \mathrm{Cu}(\mathrm{II})+\mathrm{Cu}(0)$. $\mathrm{The}$ $\mathrm{Cu}$ (II) ions arising from the disproportionation can be reduced at more negative potentials than the reduction of $\mathrm{Cu}(\mathrm{II})$ diffusing from solution towards to electrode surface. The above-mentioned dependence on scan rates and $\mathrm{Cu}(\mathrm{II})$ concentrations supported this assumption because the increase of these parameters caused the absence of both divided signals $\mathrm{c}_{11}$ and $\mathrm{c}_{12}$. Due to the pre-peak $I_{p p}$ of the signal $c_{2}$, we have to consider the presence of a reaction preceding the electron transfer. This reaction could be associated with the replacement of chloride anions specifically adsorbed on electrode surface by electroactive species such as $\mathrm{Cu}(\mathrm{II})$ and/or $\mathrm{Cu}(\mathrm{I})$. Similar behavior characterized by $I_{p p}$ was also observed for cadmium and nickel in chloride solutions [14-17].

\subsection{Electrode process of copper ions on $\mathrm{Hg}-\mathrm{PGEb}$}

Cyclic voltammograms of $\mathrm{CuSO}_{4}$ in $0.05 \mathrm{M}$ borax $(\mathrm{pH}$ 9.2) on the Hg-modified carbon electrode ( $\mathrm{Hg}-\mathrm{PGEb})$ were measured in the potential range from $-0.4 \mathrm{~V}$ to $0.1 \mathrm{~V}$. Experimental conditions, including the preparation of the $\mathrm{Hg}$-modified carbon electrode $\mathrm{Hg}$-PGEb, were as described in previously published papers [3,4,50-52]. We found that the stabilization of electrode system was reached by the fifth cycle. Voltammetric curves obtained under these conditions are shown in Fig. 2. The cathodic peak c corresponds to the reduction process $\mathrm{Cu}(\mathrm{II})+\mathrm{e}^{-} \rightarrow \mathrm{Cu}(\mathrm{I})$, including the abovementioned disproportionation. The reduced $\mathrm{Cu}(0)$ is able to form an amalgam with $\mathrm{Hg}$, which dissolves anodically (peak a). The differences between cathodic and anodic peak potentials were 73 and $208 \mathrm{mV}$ for scan rates of 25 and $800 \mathrm{mV} / \mathrm{s}$, respectively. The effect of thickness $(138 \mathrm{~nm}, 275 \mathrm{~nm}$, and $550 \mathrm{~nm}$ ) of $\mathrm{Hg}$-film on the peak height is shown in the insert in Fig. 2. The bilogarithmic dependence of current density $j$ on scan rate, $\log j_{c}=f(\log v)$, yielded a slope of 0.78 , suggesting a process controlled by diffusion but influenced by adsorption/desorption processes on the electrode surface. The Figs. 2B and C represent results of application of elimination function E4. Due to peakcounterpeak signals for lower scan rates (Fig. 2B), E4 signalized the reduction process of $\mathrm{Cu}$ in adsorption state $[38,39,41]$. For higher scan rates (Fig. 2C) the effect of adsorption is not obvious. The elimination procedure enhanced the signal more than nine times for both scan rate ranges compared to CV alone. 

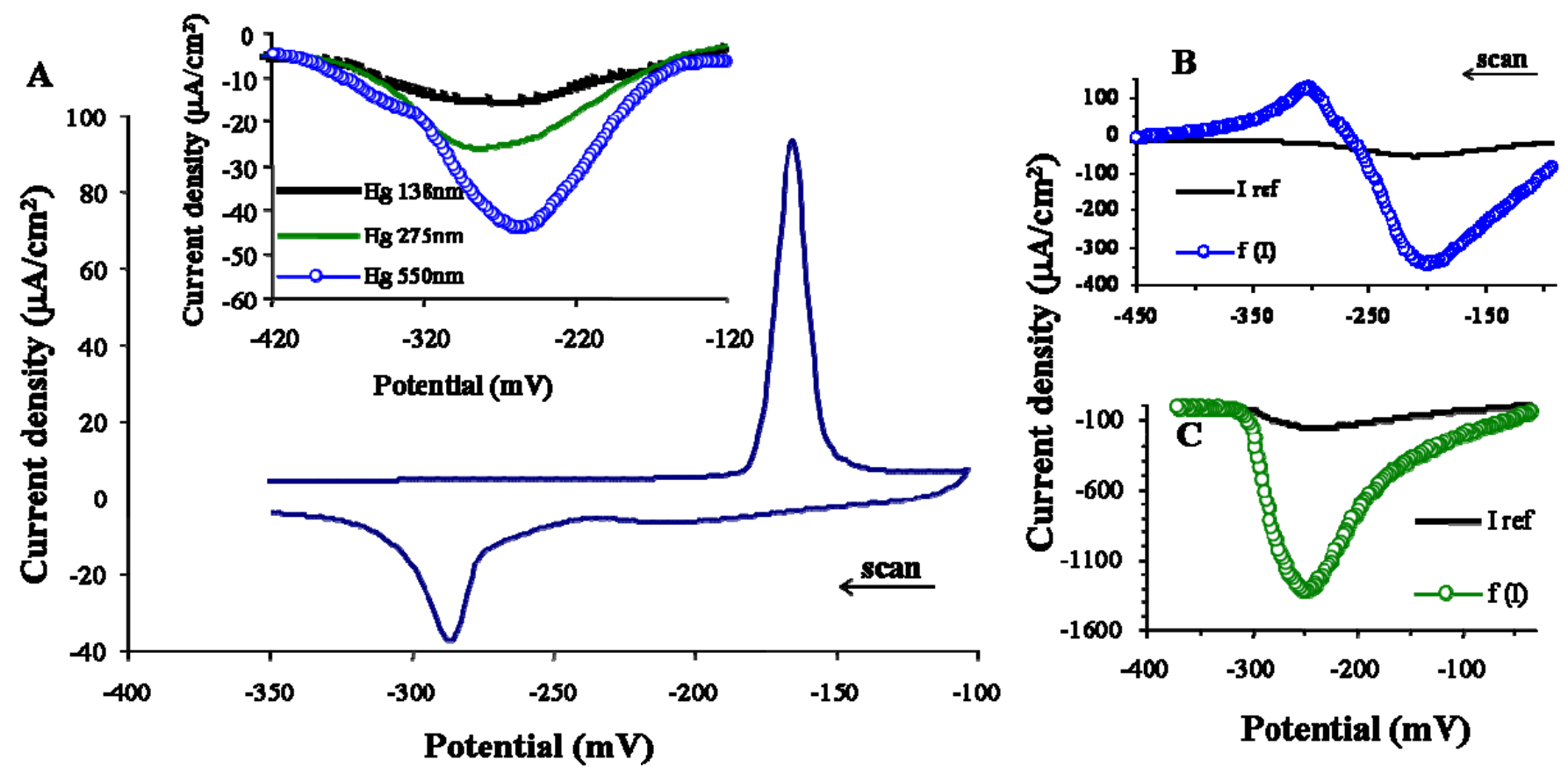

Figure 2. Voltammograms of $15 \mu \mathrm{M} \mathrm{CuSO}_{4}$ in $0.05 \mathrm{M}$ borax on $\mathrm{Hg}-\mathrm{PGEb}$ at $\mathrm{pH}$ 9.2. (A) Cyclic voltammogram of $15 \mu \mathrm{M} \mathrm{CuSO}_{4}$ in $0.05 \mathrm{M}$ borax on $\mathrm{Hg}-\mathrm{PGEb}$, scan rate 25 $\mathrm{mV} / \mathrm{s}$, thickness of $\mathrm{Hg}$ layer $275 \mathrm{~nm}$. Insert: cathodic peaks of $15 \mu \mathrm{M} \mathrm{CuSO}_{4}$ with different $\mathrm{Hg}$ layer thicknesses $(138 \mathrm{~nm}, 275 \mathrm{~nm}$, and $550 \mathrm{~nm})$. (B) Linear sweep voltammograms $\left(\mathrm{I}_{\mathrm{ref}}\right)$ and elimination voltammograms (EVLS) for scan rates of 50, 100, and $200 \mathrm{mV} / \mathrm{s}$, reference scan rate $100 \mathrm{mV} / \mathrm{s}$., (C) Linear sweep voltammograms $\left(\mathrm{I}_{\text {ref }}\right)$ and elimination voltammograms (EVLS) for scan rates of 200,400 , and $800 \mathrm{mV} / \mathrm{s}$, reference scan rate $400 \mathrm{mV} / \mathrm{s}$.

\subsection{Detection of purine-copper complexes on PIGE and Hg-PGEb}

The change of cathodic and anodic signals of $\mathrm{Cu}$ (II) in $\mathrm{NaCl}$ on PIGE electrode after addition of adenine (Ade) is shown in Fig. 3. With increasing Ade concentration, the second cathodic signal $\left(\mathrm{c}_{2}\right)$ gradually disappeared, the second anodic peak $\left(a_{2}\right)$ decreased, and the first anodic peak $\left(a_{1}\right)$ increased (Fig. 3A). The distribution diagram (MEDUSA) revealed two $\mathrm{Cu}$-Ade complexes containing cuprous $\mathrm{Cu}$ (Ade) and/or cupric ions $\mathrm{Cu}$ (Ade) $)_{2}$ with ratios dependent on concentrations of copper ions and ligands. Under our experimental conditions, $\mathrm{Cu}$ (Ade) concentrations exceeded $\mathrm{Cu}(\mathrm{Ade})_{2}$ concentrations by at least two orders of magnitude. As in experiments in the absence of Ade (samples containing only copper ions), the EVLS revealed important information about electrode processes. The function $\mathrm{E} 4$ detected two processes in the first peak $\mathrm{c}_{1}\left(\mathrm{c}_{11}\right.$ and $\mathrm{c}_{12}$ in Fig. 3B) and also a change in the peak $\mathrm{c}_{2}$ with the addition of Ade. While the process $\mathrm{c}_{11}$ corresponds to the $\mathrm{Cu}(\mathrm{II})$ reduction to $\mathrm{Cu}(\mathrm{I})$ at electrode surface, the process $\mathrm{c}_{12}$ represents the reduction of $\mathrm{Cu}(\mathrm{II})$ arising from the disproportionation step. We assume that the decrease of signal $\mathrm{c}_{12}$ upon addition of Ade is due to embedding of partially reduced $\mathrm{Cu}$ (II) into a copper-Ade complex. This idea is supported by fact that the peak $\mathrm{c}_{12}$ also decreased with increasing $\mathrm{Cu}$ concentration. 

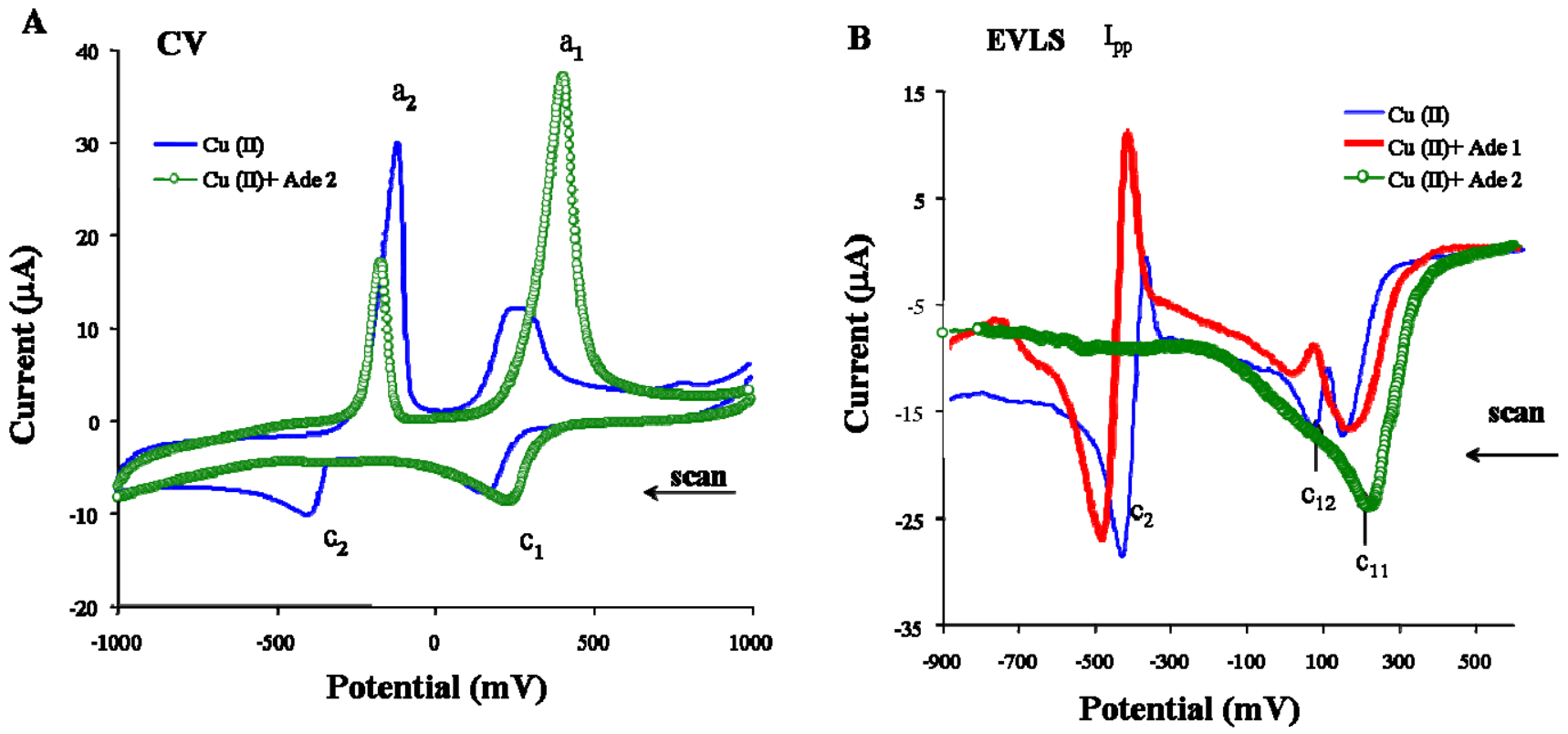

Figure 3. (A) Cyclic voltammograms of $\mathrm{CuCl}_{2}$ with and without adenine on PIGE, scan rate $25 \mathrm{mV} / \mathrm{s}, \mathrm{pH}$ 6. (B) EVLS signals of cathodic processes of $0.5 \mathrm{mM} \mathrm{CuCl} 2$ and $\mathrm{CuCl}_{2}$ with adenine (Ade 1: $70 \mu \mathrm{M}$, Ade 2: $280 \mu \mathrm{M}$ ); reference scan rate $100 \mathrm{mV} / \mathrm{s}, \mathrm{pH} 6$.

For the detection of $\mathrm{Cu}$-purine complex on PIGE, anodic stripping voltammetry (ASV) can be used. The accumulation potential $(-50 \mathrm{mV})$ and accumulation time $(60 \mathrm{~s})$ were chosen to monitor the formation of the Cu-purine complex. The ASV and corresponding EVLS signals for adenine and guanine are shown in Fig. 4A and 4B, respectively. It is clear from our results that adenine provides higher ASV and EVLS signals than guanine. Moreover EVLS detected two ASV responses which will be described elsewhere. Hason et al. found that Hg-modified graphite/carbon electrodes are suitable for sensitive electrochemical detection of acid-treated (hydrolyzed) DNA (hODN) in the presence of the copper ions [4]. The procedure is based on the cathodic stripping of the electrochemically accumulated hODN-Cu(I) complex from the thin-film mercury modified graphite/carbon electrode surface. Whereas $\mathrm{Cu}$-purine complexes on PIGE were detected by the anodic stripping technique, the detection of $\mathrm{Cu}$-purine complexes on $\mathrm{Hg}$-PGEb was carried out by means of cathodic stripping technique. The LSV ( $\mathrm{I}_{\text {ref }}$ ) and EVLS curves are shown in Fig. 4C and 4D for adenine and guanine, respectively. It was found that EVLS signals of both purines were increased relative to LSV: the amplification was 2.5 fold for Ade and 1.5 fold for Gua using PIGE and 17.2 fold for Ade and 11.1 fold for Gua using Hg-PGEb. Using EVLS we observed: a) higher CSV and corresponding EVLS signals than ASV signals, b) higher signals for adenine than guanine at both electrodes, and c) different E4 signals for adenine and guanine. In the case of ASV, the elimination procedure increased the corresponding signals (Fig. 4A and B), mainly due to responses at more positive potentials, but in the case of CSV this procedure yielded not only more sensitive, but totally different signals for adenine and guanine (Fig. 4C and D). The differences in the EVLS signals between ASV and CSV are probably related to different behaviors of $\mathrm{Cu}$-Ade and $\mathrm{Cu}-\mathrm{Gua}$ on $\mathrm{Hg}$-film. Based on the existence of the peak-counterpeak EVLS signal, we assume that an adsorption of $\mathrm{Cu}-\mathrm{Gua}$ takes place before its stripping. 

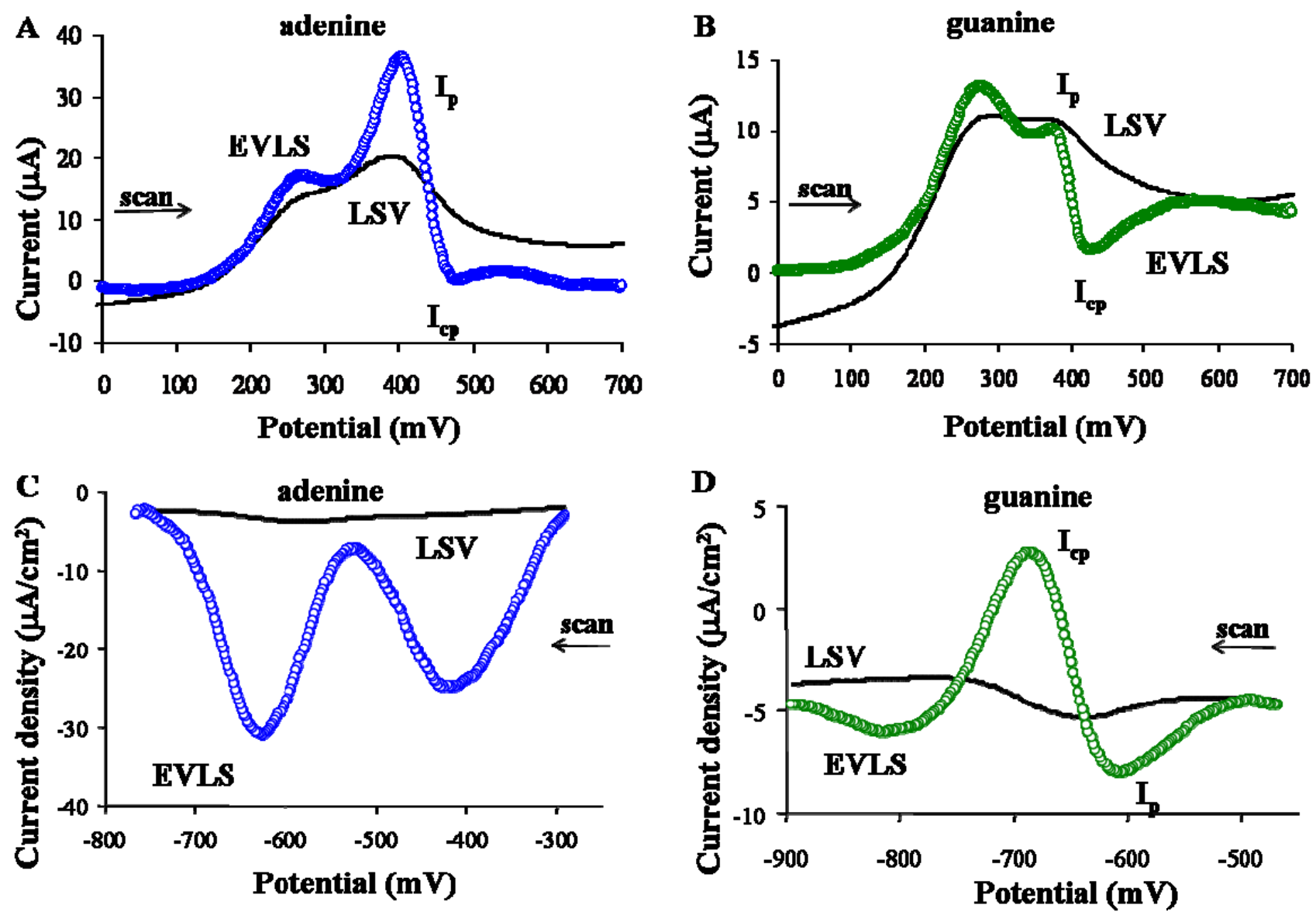

Figure 4. A) and B) Anodic stripping voltammograms on PIGE; time of accumulation $60 \mathrm{~s}$, potential of accumulation $-50 \mathrm{mV}, \mathrm{pH}$ 6. (A) LSV and EVLS curves of $\mathrm{CuCl}_{2}$ with adenine; (B) LSV and EVLS curves of $\mathrm{CuCl}_{2}$ with guanine, scan rate $100 \mathrm{mV} / \mathrm{s}$. (C) and (D) Cathodic stripping voltammograms on $\mathrm{Hg}-\mathrm{PGEb}$; time of accumulation $60 \mathrm{~s}$, potential of accumulation $-256 \mathrm{mV}, \mathrm{pH}$ 9.2. (C) LSV and EVLS curves of $\mathrm{CuSO}_{4}$ with adenine, scan rate $200 \mathrm{mV} / \mathrm{s}$; (D) LSV and EVLS curves of $\mathrm{CuSO}_{4}$ with guanine, scan rate $50 \mathrm{mV} / \mathrm{s}$.

\subsection{Statistical evaluation of experiments on PIGE and Hg-PGEb}

To obtain confidence ellipses [46,53], twelve samples of $10 \mu \mathrm{M} \mathrm{CuCl}_{2}$ in $0.5 \mathrm{M} \mathrm{NaCl}(\mathrm{pH}$ 6) on PIGE at a scan rate of $100 \mathrm{mV} / \mathrm{s}$ (Fig. 5A) and twelve samples of $15 \mu \mathrm{M} \mathrm{CuSO}_{4}$ in $0.05 \mathrm{M}$ borax on $\mathrm{Hg}-\mathrm{PGEb}$ (pH 9.2; thickness of $\mathrm{Hg}$ layer, 275nm) at a scan rate of $400 \mathrm{mV} / \mathrm{s}$ were measured (Fig. 5B). Confidence ellipses (CEs) with 95\% reliability, including the ratio of the shorter to larger axis (b/a) and the area, were calculated by MATLAB 6.5 program. The first Fourier coefficients after the transformation of the curves are visualized by the points surrounded by CE. The CEs for both systems were characterized by the ratio $\mathrm{b} / \mathrm{a}=0.116$ with an area of 0.009 (Fig. 5A) for PIGE and $\mathrm{b} / \mathrm{a}=0.026$ with an area of 1.745 for $\mathrm{Hg}-\mathrm{PGEb}$ (Fig. 5B). These parameters indicate some deterministic effect in the repeated measurements of chosen $\mathrm{CuCl}_{2}$ electrolyte. Higher ratio and lower surface (PIGE) indicate a lower systematic error; lower ratio and higher surface (Hg-PGEb) a higher systematic error. In Fig. 5A, points 1, 11, and 12 are out of the 95\% CE and were eliminated using the OUTLY program 
(written in MATLAB). After the elimination of these points, we obtained a ratio $\mathrm{b} / \mathrm{a}=0.088$ with the area of 0.002 for PIGE.

$\mathbf{A}$

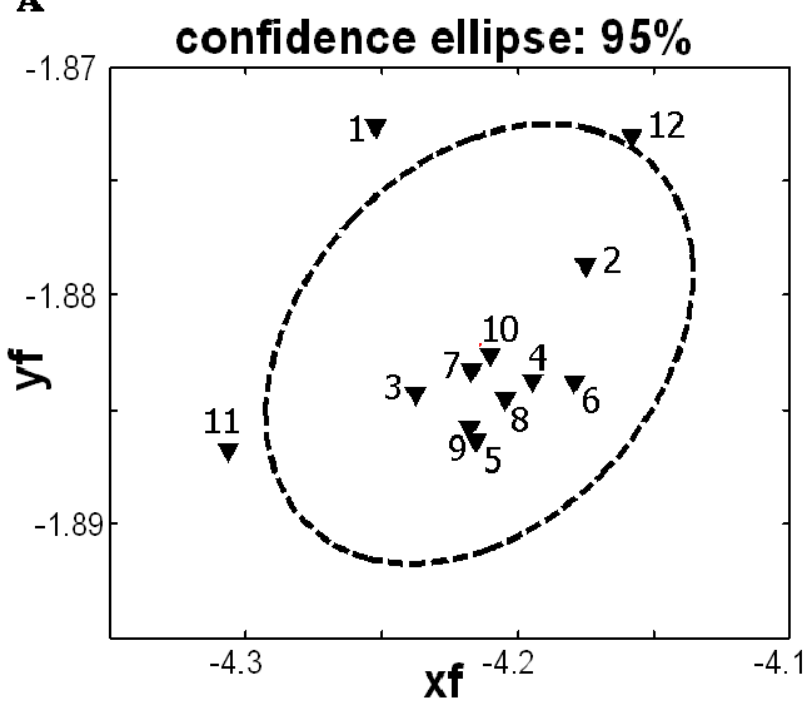

B

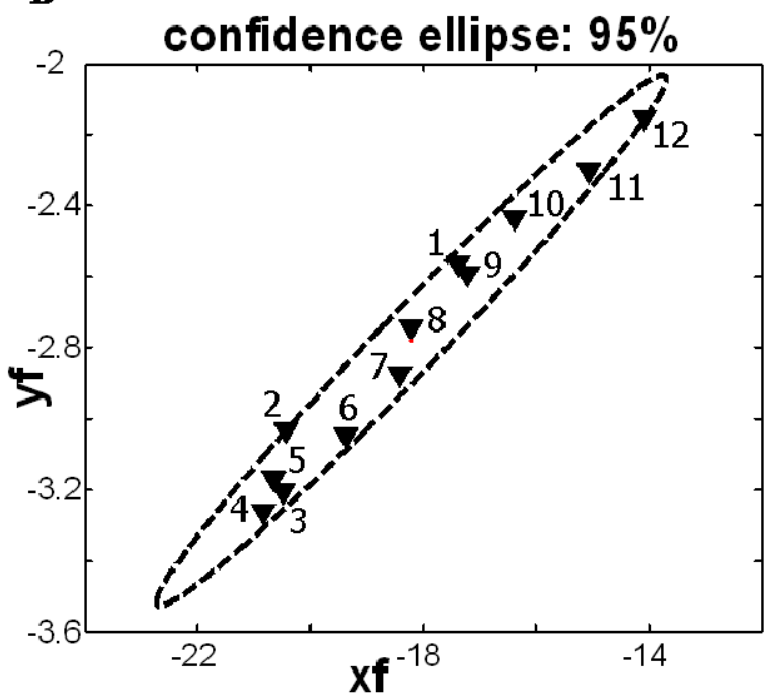

Figure 5. Confidence ellipses of $\mathrm{Cu}$ (II) (A) on PIGE $\left(10 \mu \mathrm{M} \mathrm{CuCl}_{2}\right.$ in $0.5 \mathrm{M} \mathrm{NaCl}, \mathrm{pH} 6$, scan rate $100 \mathrm{mV} / \mathrm{s}$ ), (B) on $\mathrm{Hg}$-PGEb (thickness of $\mathrm{Hg}$ layer $275 \mathrm{~nm}, 15 \mu \mathrm{M} \mathrm{CuSO}_{4}$ in $0.05 \mathrm{M}$ borax, $\mathrm{pH} 9.2$, scan rate $400 \mathrm{mV} / \mathrm{s})$.

\section{Conclusion}

Our study of redox systems of $\mathrm{Cu}$ (II) on two modified graphite electrodes (PIGE and $\mathrm{Hg}$-PGEb) in the presence or absence of purines contributes to the family of papers that deals with microdetection of purine bases and/or bases released from oligonucleotide chains by means of acid hydrolysis [3,7,2628,50-52,54,55]. Deeper understanding of individual electrochemical steps in the $\mathrm{Cu}(\mathrm{II})$ reduction and higher sensitivity of $\mathrm{Cu}$-purine detection was achieved by the application of EVLS to voltammetric curves. On the basis of the elimination function E4, we were able to distinguish between double-step and single-step reduction processes in the case of PIGE and Hg-PGEb, respectively. On PIGE, this EVLS function revealed reduction steps in which the formation of $\mathrm{Cu}(\mathrm{I})$, its disproportionation, and a surface reaction controlled by kinetics (e.g., adsorption/desorption, surface diffusion, nucleation) take place. Compared with PIGE, the surface of $\mathrm{Hg}$-PGEb influences the reduction of $\mathrm{Cu}$ (II) such that the EVLS function E4 indicates the process in adsorption state. It was found that both stripping signals (i.e., ASV for PIGE and CSV for Hg-PGEb), indicated higher signals for the $\mathrm{Cu}$-Ade complex than for the $\mathrm{Cu}-\mathrm{Gua}$ complex. To evaluate the reproducibility of measurements, statistical data processing was carried out. Particularly, the confidence ellipses were plotted from twelve measurements for both electrode PIGE and Hg-PGEb. The systematic error was lower for PIGE than for Hg-PGEb.

The structure of $\mathrm{Cu}$-purine complexes and the valence of $\mathrm{Cu}$ embedded in these complexes have been unclear. The formation of a $\mathrm{Cu}(\mathrm{I})$-purine complex was supported by our EVLS results. We propose that (a) EVLS, in connection with the stripping procedure and optimal experimental conditions, can be useful tool offering quantitative and qualitative insight into the microanalysis of 
purine derivatives, including structures of complexes and valences of metals, and (b) EVLS can be used to develop simple, fast, low-cost biosensors for the study of DNA hybridization and damage [56-59].

\section{Acknowledgement}

This work was supported by the grants INCHEMBIOL MSM0021622412, BIO-ANAL-MED LC06035, and COST OC174 from the Ministry of Education, Youth and Sports and by the grants A100040602 and A400040804 from the Grant Agency of the Academy of Sciences of the Czech Republic. The authors are indebted to Prof. M. Holik for discussion concerning confidence ellipses and to Mrs. I. Postbieglova for skillful technical assistance.

\section{References}

1. Palecek, E.; Jelen, F. Electrochemistry of Nucleic Acids; Elsevier: Amsterdam, 2005; pp. 74-173.

2. Fadrna, R.; Yosypchuk, B.; Fojta, M.; Navratil, T.; Novotny, L. Voltammetric determination of adenine, guanine, and DNA using liquid mercury free polished silver solid amalgam electrode. Anal. Lett. 2004, 37, 399-413.

3. Farias, P.A.M.; Wagener, A.D.; Castro, A.A. Ultratrace determination of adenine in the presence of copper by adsorptive stripping voltammetry. Talanta 2001, 55, 281-290.

4. Hason, S.; Jelen, F.; Fojt, L.; Vetterl, V. Determination of picogram quantities of oligodeoxynucleotides by stripping voltammetry at mercury modified graphite electrode surfaces. J. Electroanal. Chem. 2005, 577, 263-272.

5. Jelen, F.; Kourilova, A.; Pecinka, P.; Palecek, E. Microanalysis of DNA by stripping transfer voltammetry. Bioelectrochemistry 2004, 63, 249-252.

6. Wang, J.; Kawde, A.B. Amplified label-free electrical detection of DNA hybridization. Analyst 2002, 127, 383-386.

7. dosSantos, M.M.C.; Lopes, C.M.L.F.; Goncalves, M.L.S. Voltammetric studies of purine bases and purine nucleosides with copper. Bioelectrochem. Bioenerg. 1996, 39, 55-60.

8. Glodowski, S.; Bilewicz, R.; Kublik, Z. Determination of traces of purine by cathodic stripping voltammetry at the hanging copper amalgam drop. Anal. Chim. Acta 1986, 186, 39-47.

9. $\quad$ McCreery, R.L.; K., C.K. Carbon Electrodes, Marcel Dekker, 1996; 293-332.

10. Cui, H.; Zou, G.Z.; Lin, X.Q. Electrochemiluminescence of luminol in alkaline solution at a paraffin-impregnated graphite electrode. Anal. Chem. 2003, 75, 324-331.

11. Gong, J.M.; Lin, X.G. Facilitated electron transfer of hemoglobin embedded in nanosized Fe3O4 matrix based on paraffin impregnated graphite electrode and electrochemical catalysis for trichloroacetic acid. Microchem. J. 2003, 75, 51-57.

12. Komorsky-Lovric, S. Redox kinetics of adriamycin adsorbed on the surface of graphite and mercury electrodes. Bioelectrochemistry 2006, 69, 82-87.

13. Walcarius, A. Zeolite-modified paraffin-impregnated graphite electrode. J. Solid State Electrochem. 2006, 10, 469-478. 
14. Orinakova, R.; Streckova, M.; Trnkova, L.; Rozik, R.; Galova, M. Comparison of chloride and sulphate electrolytes in nickel electrodeposition on a paraffin impregnated graphite electrode. $J$. Electroanal. Chem. 2006, 594, 152-159.

15. Orinakova, R.; Trnkova, L.; Galova, M.; Supicova, M. Application of elimination voltammetry in the study of electroplating processes on the graphite electrode. Electrochim. Acta 2004, 49, 3587-3594.

16. Rozik, R.; Trnkova, L. Cadmium reduction process on paraffin impregnated graphite electrode studied by elimination voltammetry with linear scan. J. Electroanal. Chem. 2006, 593, 247257.

17. Streckova, M.; Orinakova, R.; Rozik, R.; Trnkova, L.; Galova, M. A study of nickel electrodeposition on paraffin-impregnated graphite electrode. Helvetica Chim. Acta 2006, 89, 622-634.

18. McCreery, R.L. Electron Transfer Kinetics at Carbon Electrodes; Marcel Dekker, 1991; pp. 221-374.

19. Dryhurst, G.; Elving, P.J. Electrochemical Oxidation of Adenine - Reaction Products and Mechanisms. J. Electrochem. Soc. 1968, 115, 1014-1020.

20. Goyal, R.N.; Brajtertoth, A.; Dryhurst, G. Further Insights into the Electrochemical Oxidation of Uric-Acid. J. Electroanal. Chem. 1982, 131, 181-202.

21. Goyal, R.N.; Rajeshwari, I.; Mathur, N.C. Electrochemical Oxidation of Uric-Acid and 6Thiouric Acid. Bioelectrochem. Bioenerg. 1990, 24, 355-360.

22. Ibrahim, M.S.; Temerk, Y.M.; Kamal, M.M.; Ahmed, G.A.W.; Ibrahim, H.S.M. Ultra-sensitive anodic stripping voltammetry for the determination of xanthine at a glassy carbon electrode. Microchim. Acta 2004, 144, 249-256.

23. Kachoosangi, R.T.; Banks, C.E.; Compton, R.G. Simultaneous determination of uric acid and ascorbic acid using edge plane pyrolytic graphite electrodes. Electroanalysis 2006, 18, 741747.

24. Shiraishi, H.; Takahashi, R. Accumulation of Adenine and Guanine as $\mathrm{Cu}+\mathrm{Compounds}$ at Glassy-Carbon Electrodes Followed by Anodic-Stripping Voltammetry. Bioelectrochem. Bioenerg. 1993, 31, 203-213.

25. Safavi, A.; Maleki, N.; Shams, E.; Shahbaazi, H.R. Determinaton of copper by adsorptive stripping voltammetry of its complex with adenine. Electroanalysis 2002, 14, 929-934.

26. Farias, P.A.M.; Wagener, A.D.R.; Bastos, M.B.R.; da Silva, A.T.; Castro, A.A. Cathodic adsorptive stripping voltammetric behaviour of guanine in the presence of copper at the static mercury drop electrode. Talanta 2003, 61, 829-835.

27. Farias, P.A.M.; Castro, A.A.; Wagener, A.D.R.; Junqueira, A.A. DNA determination in the presence of copper in diluted alkaline electrolyte by adsorptive stripping voltammetry at the mercury film electrode. Electroanalysis 2007, 19, 1207-1212.

28. Jelen, F.; Yosypchuk, B.; Kourilova, A.; Novotny, L.; Palecek, E. Label-Free Determination of Picogram Quantities of DNA by Stripping Voltammetry with Solid Copper Amalgam or Mercury Electrodes in the Presence of Copper. Anal. Chem. 2002, 74, 4788-4793.

29. Trnkova, L.; Dracka, O. Elimination voltammetry. Experimental verification and extension of theoretical results. J. Electroanal. Chem. 1996, 413, 123-129. 
30. Palecek, E. Oszillographische Polarographie der Nucleinsauren und ihrer Bestandteile. Naturwiss. 1958, 45, 186-187.

31. Trnkova, L.; Jelen, F.; Postbieglova, I. Application of elimination voltammetry to the resolution of adenine and cytosine signals in oligonucleotides. I. Homooligodeoxynucleotides dA(9) and dC(9). Electroanalysis 2003, 15, 1529-1535.

32. Trnkova, L.; Jelen, F.; Postbieglova, I. Application of elimination voltammetry to the resolution of adenine and cytosine signals in oligonucleotides II. Hetero-oligodeoxynucleotides with different sequences of adenine and cytosine nucleotides. Electroanalysis 2006, 18, 662669.

33. Galus, Z. Fundamentals of Electrochemical analysis; Polish Scientific Publisher PWN, 1994.

34. Scholz, F. Electroanalytical Methods, Guide to Experiment and Applications; Springer: Heidelberg, Germany, 2002.

35. Scholz, F.; Meyer, B. Electrochemical solid state analysis: state of the art. Chem. Soc. Rev. 1994, 23, 341-347.

36. Dracka, O. Theory of current elimination in linear scan voltammetry. J. Electroanal. Chem. 1996, 402, 19-28.

37. Supicova, M.; Rozik, R.; Trnkova, L.; Orinakova, R.; Galova, M. Influence of boric acid on the electrochemical deposition of Ni. J. Solid State Electrochem. 2005, 10, 61-68.

38. Trnkova, L. Elektrochemické eliminační metody. Chem. Listy 2001, 95, 518-527.

39. Trnkova, L. Identification of current nature by elimination voltammetry with linear scan. $J$. Electroanal. Chem. 2005, 582, 258-266.

40. Trnkova, L.; Friml, J.; Dracka, O. Elimination voltammetry of adenine and cytosine mixtures. Bioelectrochem. 2001, 54, 131-136.

41. Trnkova, L.; Kizek, R.; Dracka, O. Application of elimination voltammetry to adsorptive stripping of DNA. Electroanalysis 2000, 12, 905-911.

42. Trnkova, L.; Kizek, R.; Dracka, O. Appplication of elimination methods in electrochemical study of DNA. J. Biomol. Struct. Dynam. 2000, 17, 1169-70.

43. Trnkova, L.; Kizek, R.; Dracka, O. Elimination voltammetry of nucleic acids on silver electrodes. Bioelectrochem. 2002, 55, 131-133.

44. Trnkova, L.; Postbieglova, I.; Holik, M. Electroanalytical determination of d(GCGAAGC) hairpin. Bioelectrochem. 2004, 63, 25-30.

45. Mikelova, R.; Trnkova, L.; Jelen, F.; Adam, V.; Kizek, R. Resolution of overlapped reduction signals in short hetero-oligonucleotides by elimination voltammetry. Electroanalysis 2007, 19, 348-355.

46. Holik, M.; Halamek, J. Transformation of a Free-Wilson Matrix into Fourier Coefficients. Quant. Struct.-Act. Relat. 2002, 20, 422-428.

47. Souto, R.M.; Saakes, M.; Sluyters-Rehbach, M.; Sluyters, J.H. The catalysis of the electrochemical reduction of camium ions by chloride ions. J. Electroanal. Chem. 1988, 245, 167-189.

48. Grujicic, D.; Pesic, B. Reaction and nucleation mechanisms of copper electrodeposition from ammoniacal solutions on vitreous carbon. Electrochim. Acta. 2005, 50, 4426-4443. 
49. Jagner, D.; Sahlin, E.; Renman, L. Experimental and Computational Study of Species Formed During Electrochemical Stripping Oxidation of Copper in Chloride Media - Determination of Copper(Ii) in the Ng 1(-1) Range by Stripping Potentiometry. Talanta 1995, 42, 1447-1455.

50. Hason, S.; Vetterl, V. Amplified oligonucleotide sensing in microliter volumes containing copper ions by solution streaming. Anal. Chem. 2006, 78, 5179-5183.

51. Hason, S.; Vetterl, V. Microanalysis of oligodeoxynucleotides by cathodic stripping voltammetry at amalgam-alloy surfaces in the presence of copper ions. Talanta 2006, 69, 572580 .

52. Jelen, F.; Hason, S.; Trnkova, L. Microanalysis of nucleic acids bases and oligonucleotides by electrochemical stripping techniques; Research Signpost, 2007; pp. 153-171.

53. Holik, M.; Halamek, J. Calculation of the tilts of curved lines. Chemometrics Intell. Lab. Syst. 2003, 1382, 1-9.

54. Bilewicz, R.; Glodowski, S.; Kublik, Z. The influence of adenine on the electrochemical behaviour of the $\mathrm{Cu} / \mathrm{II} / / \mathrm{Cu} / 0$ / system. J. Electroanal. Chem. 1989, 274, 201-212.

55. Bilewicz, R.; Muszalska, E. Voltammetric behaviour of copper complexes with the antitumour drug 6-mercaptopurine. J. Electroanal. Chem. 1991, 300, 147-157.

56. Palecek, E.; Fojta, M. Detecting DNA hybridization and damage. Anal. Chem. 2001, 73, 74A$83 \mathrm{~A}$.

57. Thorp, H.H. Cutting out the middleman: DNA biosensors based on electrochemical oxidation. Trends Biotechnol. 1998, 16, 117-121.

58. Thorp, H.H. Reagentless detection of DNA sequences on chemically modified electrodes. Trends Biotechnol. 2003, 21, 522-524.

59. Wang, J. Towards genoelectronics: Electrochemical biosensing of DNA hybridization. Chem.Eur. J. 1999, 5, 1681-1685.

(C) 2008 by MDPI (http://www.mdpi.org). Reproduction is permitted for noncommercial purposes. 